\title{
Characteristics of organic dairy major farm types in seven European countries
}

\author{
A. Wallenbeck (D) - T. Rousing • J. T. Sørensen - A. Bieber • A. Spengler Neff • \\ B. Fuerst-Waltl • C. Winckler - C. Peiffer • F. Steininger • C. Simantke $\cdot$ S. March • \\ J. Brinkmann • J. Walczak • P. Wójcik • V. Ribikauskas • S. Wilhelmsson • T. Skjerve • \\ S. Ivemeyer
}

Received: 5 July 2018 / Accepted: 21 August 2018 /Published online: 15 September 2018

(C) The Author(s) 2018

\begin{abstract}
This study aimed to identify organic dairy major farm types (MFTs) in seven European countries, describe these MFTs in an open research database and assess central characteristics of the MFTs. This was conducted in a three-step procedure including (1) Identification of organic MFTs in seven European countries: Austria, Switzerland, Germany, Denmark, Lithuania, Poland and Sweden, based on existing data from dairy databases and consultations with experts within the respective fields of knowledge; (2) Collection of data on farm characteristics, management procedures, production level and herd health from at least 10 farms per
\end{abstract}

A. Wallenbeck · T. Skjerve

Department of Animal Breeding and Genetics, Swedish University of Agricultural Sciences, Box 7023, 75007 Uppsala,

Sweden

A. Wallenbeck $(\bowtie) \cdot S$. Wilhelmsson

Department of Animal Environment and Health, Swedish

University of Agricultural Sciences, Box 234, 53232 Skara,

Sweden

e-mail: anna.wallenbeck@slu.se

T. Rousing $\cdot$ J. T. Sørensen

Department of Animal Science, Aarhus University, Aarhus, Denmark

A. Bieber - A. Spengler Neff

Research Institute of Organic Agriculture, FiBL, Department of Livestock Sciences, Ackerstrasse 113, 5070 Frick, Switzerland

B. Fuerst-Waltl · C. Winckler · C. Peiffer

Department of Sustainable Agricultural Systems, University of

Natural Resources and Life Sciences (BOKU), Gregor

Mendel-Strasse 33, 1180 Vienna, Austria
MFT and country and (3) Creating an open research database on MFT characteristics, description of essential characteristics of MFTs and assessment of similarities and differences between farms within and across MFTs. The results indicate variations in herd characteristics such as production level, herd size, farm size, housing system, milking system and cow health status between organic dairy farms in these seven European countries. It also indicates variations in management strategies such as feeding, animal health management and recruitment strategies across the organic dairy sector in Europe. These variations seem to be associated with

F. Steininger

ZuchtData EDV-Dienstleistungen GmbH, Dresdner Strasse 89/19, A-1200 Vienna, Austria

C. Simantke $\cdot$ S. Ivemeyer

Section of Farm Animal Behaviour and Husbandry, Faculty of Organic Agricultural Sciences, Nordbahnhofstraße 1a, University of Kassel, 37213 Witzenhausen, Germany

\section{S. March · J. Brinkmann}

Thuenen-Institute of Organic Farming, Federal Research Institute for Rural Areas, Forestry and Fisheries, Trenthorst 32, 23847 Westerau, Germany

J. Walczak · P. Wójcik

National Research Institute of Animal Production, 32-083 Balice, Poland

V. Ribikauskas

Department of Food Safety and Quality, Lithuanian University of Health Sciences, Veterinary Academy, Tilzes 18, 47181 Kaunas, Lithuania 
differences between regions and countries in the conditions for organic dairy production, such as topography, land availability and regulations.

Keywords Organic dairy production - Farm size . Housing · Production level $\cdot$ Health $\cdot$ Feeding $\cdot$ Breeding

\section{Introduction}

Consumer demand for organic products is increasing (European Commission 2014; Eurostat 2016) and this, together with the premium price for organic products, has prompted an increase in organic production (Rosati and Aumaitre 2004; Escribano et al. 2015). Moreover, organic production contributes public goods such as biodiversity and human and animal health and welfare (Jespersen et al. 2017). In Europe, the organic dairy sector has seen a steady increase, reaching a market share of between 2 and $11 \%$ in 2016 depending on country, with the main markets being in Western Europe (Sørensen et al. 2006). Consequently, organic dairy production in the EU has almost doubled since 2007, and by 2016 constituted more than $2.8 \%$ (4.1 million metric tons) of total EU milk production (Willer and Lernoud 2018). Organic dairy production is characterised by high-roughage diets based on home-grown feedstuffs, outdoor access on pasture and restrictive use of antibiotics (EC 2007). In organic dairy production, animal health and welfare is promoted by preventative actions such as using suitable breeds, feed, management and housing system. Accordingly, compared with conventional farms, organic dairy cattle farms have a higher amount of pasture-based feeding systems and a lower amount of concentrate feeding (Kristensen and Kristensen 1998; Valle et al. 2007; Thomassen et al. 2008) and on average a lower use of medicines (Richert et al. 2013; Van Wagenberg et al. 2016). Some of the major challenges within European organic dairy production are preventative handling of mastitis and metabolic diseases (Bennedsgaard et al. 2010; Ivemeyer et al. 2012), improvement of production efficiency based on local feed resources and development of suitable breeding strategies (Röös et al. 2018).

The organic dairy cattle sector must adapt to differences in topography, infrastructure, national and regional organic regulations, traditions and typical management procedures. Consequently, organic dairy farm types vary across Europe. These differences arise within individual countries (e.g. Ivemeyer et al. 2017), but can be expected to be of even greater magnitude between European countries. Thus, there is not one, but many, organic dairy production systems in Europe. However, no systematic mapping of organic dairy production environments in Europe is available at present. Thus, an essential step in the development process in order to enhance knowledge exchange within the European organic dairy sector, and also to provide evidencebased information for advisors, policymakers and regulation developers, is to identify and map major organic dairy farm types in Europe.

\section{Aim}

The aim of this study was to identify organic dairy major farm types (MFTs) in seven European countries, describe these MFTs in an open research database and assess central characteristics of the MFTs.

\section{Material and methods}

This study was conducted in a three-step procedure:

(1) Identification of organic MFTs in seven European countries: Austria (AT), Switzerland (CH), Germany (DE), Denmark (DK), Lithuania (LT), Poland (PL) and Sweden (SE), based on existing data from dairy databases and consultations with experts (production advisors (including veterinarians) and researchers) within the respective fields of knowledge.

(2) Collection of data on farm characteristics (herd size and structure, housing and milking system), management procedures (related to feed, health and breeding), production level and herd health from at least 10 farms per MFT (Table 2).

(3) Creation of an open research database on MFT characteristics, description of essential characteristics of MFTs and assessment of similarities and differences between farms within and across MFTs.

This three-step procedure was chosen in order to identify and describe some major variations and patterns 
in the European organic dairy sector, and was not intended to give a representative quantification of characteristics of European organic dairy farms.

\section{Identification of MFTs in seven European countries}

The MFTs in each country were identified according to a standardised protocol that covered four criteria: geographical location, herd size, housing type and production level. The protocol was completed using data from different national data sources and expert panel interviews, although methods for MFT identification varied to some extent between countries (Table 1). The relevance of the criteria considered also varied between countries, e.g. there is greater variation in geographical location and milk production level in Switzerland and Austria than in Denmark. Thus, the main criteria included in MFT identification also varied between countries (Table 1).
Collecting data on farm characteristics for each MFT

The characteristics of each farm type were investigated in an in-depth farm survey that included detailed questions on approximately 90 items, such as farm location, housing and milking system, herd size and structure, production level, herd health status and preventive health management, feeding including ratio formulation, pasture management, fodder production and breeding strategies, including breeds kept on the farm and reproduction techniques used. For details of the survey, see OrganicDairyHealth database (2018). The survey protocol was developed jointly by all partners, translated into native languages and used in all countries. Data collection according to the survey protocol was performed as interviews, questionnaires, data collection from databases or a combination of these methods. Methods for identification of farms for inclusion in data collection and methods for data collection varied between countries (Table 2). Protocol information was

Table 1 Information source, identification method and main criteria included in identification of major farm types (MFTs) of organic dairy farms in the seven countries included in the analysis

\begin{tabular}{|c|c|c|c|}
\hline Country & Information source & MFT identification method & $\begin{array}{l}\text { Main criteria included in } \\
\text { MFT identification }\end{array}$ \\
\hline Austria & $\begin{array}{l}\text { National cattle database and data from an } \\
\text { on-farm research project }\end{array}$ & $\begin{array}{l}\text { Expert opinion (researchers and } \\
\text { representatives of breeding organisations) } \\
\text { based on collected information }\end{array}$ & $\begin{array}{l}\text { Herd size, housing type, } \\
\text { location/level of intensity } \\
\text { of farming }\end{array}$ \\
\hline Switzerland & $\begin{array}{l}\text { National cattle database and expert panel } \\
\text { interview }\end{array}$ & $\begin{array}{l}\text { Expert opinion (researchers and advisors) } \\
\text { based on collected information }\end{array}$ & Location, production level \\
\hline Germany & $\begin{array}{l}\text { National agricultural statistical database, data } \\
\text { from on-farm research projects and expert } \\
\text { panel interview }\end{array}$ & $\begin{array}{l}\text { Cluster analysis, expert opinion based on } \\
\text { results from cluster analysis (Ivemeyer et al. } \\
\text { 2017) }\end{array}$ & $\begin{array}{l}\text { Herd size, housing type, } \\
\text { location, production level }\end{array}$ \\
\hline Denmark & $\begin{array}{l}\text { National cattle database and expert panel } \\
\text { interview }\end{array}$ & $\begin{array}{l}\text { Expert opinion (researchers and advisors) } \\
\text { based on collected information }\end{array}$ & $\begin{array}{l}\text { Housing type, production } \\
\text { level }\end{array}$ \\
\hline Lithuania & $\begin{array}{l}\text { Data from the organic certification } \\
\text { organisation Ekoagros }\end{array}$ & $\begin{array}{l}\text { Expert opinion (researchers) based on collect- } \\
\text { ed information }\end{array}$ & Herd size, housing type \\
\hline Poland & $\begin{array}{l}\text { National cattle database and data from } \\
\text { Agricultural and Food Quality Main } \\
\text { Inspection }\end{array}$ & Principal components analysis ${ }^{1}$ & Housing type, location \\
\hline Sweden & $\begin{array}{l}\text { National cattle database (Växa 2014) and data } \\
\text { from organic certification organisation } \\
\text { KRAV }\end{array}$ & $\begin{array}{l}\text { Expert opinion (researchers and production } \\
\text { advisors from Växa) based on collected } \\
\text { information }\end{array}$ & $\begin{array}{l}\text { Herd size, production level } \\
\text { (nested within milking } \\
\text { equipment type) }\end{array}$ \\
\hline
\end{tabular}

\footnotetext{
${ }^{1}$ Poland: MFTs were defined using data from 463 organic dairy farms obtained through the national cattle database. Using PROC FACTOR method = prin in SAS 9.4® software (SAS Institute Inc. 2017), principal component analysis (PCA) was used to identify variables that explained the largest degree of variance. Input variables were the continuous variables 'herd size' and 'milk yield', and the binominal variables 'location mountain', 'location lowland', 'loose housing' and 'tie-stall'. Number of components to be retained was decided using Kaiser's criterion. On the basis of the PCA, location mountain, location lowland, loose housing and tie-stall were chosen as defining variables for MFTs. However, this created a farm type with too few observations (location mountain, loose housing; $n=6$ ). The two mountain farm types were therefore merged into one, and three final MFTs were defined (lowland, loose housing; lowland, tie-stall; mountain, loose housing and tie-stall)
} 
collected from at least 10 farms per farm type. A survey was considered complete when critical information on housing and milking system, herd size and structure, production level and herd health status was recorded. In total, 715 completed surveys were obtained. All data collected referred to production year 2014, except for Denmark, for which information for production year 2015 was recorded.

Building a database on organic dairy farm characteristics

Data obtained in the data collection process were compiled into a common database with information on farm level to be used as input to other work packages in the OrganicDairyHealth project (OrganicDairyHealth database 2018). Database information summarised on MFT level is publicly available and can be accessed at http://projects.au.dk/coreorganicplus/researchprojects/organicdairyhealth/database-summary/. It is intended for use in future research projects. The database is extensive and includes more than 250 variables describing detailed characteristics of the 715 farms surveyed. In this paper, we do not aim to provide a complete description of all recorded characteristics, but focus on describing critical farm, herd and management characteristics.

\section{Data processing}

All data were edited in Microsoft Excel 2013 (Microsoft Inc., 2013) and SAS® 9.4 (SAS Institute Inc., 2013). Descriptive statistics on variations within and between MFTs were calculated using SAS® 9.4 (SAS Institute Inc., 2013). Graphical illustrations were created in RStudio ver1.0.143 (RStudio Team, 2016). The final dataset analysed comprised 22 variables and 715 farm observations from the seven countries included in the study.

Table 2 Methods used for data collection and for farm identification and number of farms with a completed survey in each of the seven countries included in the analysis

\begin{tabular}{lll}
\hline Country $\quad$ Methods for data collection & Methods for identification of farms & $\begin{array}{l}\text { Number of } \\
\text { farms with } \\
\text { complete } \\
\text { surveys }\end{array}$ \\
\hline
\end{tabular}

Austria Interviews by phone ( $57 \mathrm{farms})$, in combination with Farms included in another research project and farms data from the national cattle database Rinderdatenverbund (RDV) and another research $\operatorname{project}^{1}(27$ farms)

Switzerland Interviews by main or phone in combination with data from the national cattle database

Germany Interviews on farms (13 farms) and interviews by phone (28 farms), in combination with data collected in other research projects

Denmark Interviews on farms in combination with data from the national cattle database

Lithuania Interviews on farms ( 9 farms), interviews by phone (12 farms), paper questionnaire (19 farms) and data from the organic certification organisation Ekoagros

Poland National cattle database and data from Agricultural and Food Quality Main Inspection

Sweden Internet-based questionnaire identified by performance testing and organic organisations that best fitted the major farm type (MFT) criteria

Organic dairy farms with completed records for 2014 were selected from a FiBL database. Of 142 farms fulfilling MFT criteria, 10 farms per MFT were randomly selected within geographical regions

Farms included in other research projects and farms in the research database that best fitted the MFT criteria

Farms included in other research studies. All fitting the DK MFT-profiles, thus including farms with robot milking

Farms that best fitted the MFT criteria and then randomly selected within geographical regions

All farms with sufficient data in the Polish databases and fulfilling the MFT criteria

The questionnaire was e-mailed to 400 randomly selected KRAV-certified organic dairy farms in Sweden. Of these, 108 entered and 81 completed the survey
60

20

\footnotetext{
${ }^{1}$ Records collected within the project 'Analysis and optimization of production efficiency and environmental impact within the Austrian cattle production' (Efficient Cow), Project No. 100861, were used
} 


\section{Results}

\section{Identified MFTs}

The number of MFTs identified varied between countries. Definitions of the MFTs identified in each partner country are presented in Table 3 .

Farm size and structure

Farm size, in terms of number of cows and area of arable land, varied between MFTs (median 11 to 143 lactating cows per herd, median 28 to 385 ha per farm). Size showed skewed distributions within MFTs, as indicated by the interquartile ranges (IQRs) and the relationships between medians and IQRs (Table 4). The availability of arable land for pasture and access to semi-natural pasture varied between regions, and thus between MFTs (Table 4). The age distribution of the cows in the herd varied between a MFT median of 16.7 and $35.8 \%$ for first-parity cows in the herd. Age distribution also varied between countries, with a higher proportion of first- and second-parity cows in MFTs in Austria, Denmark and Sweden and a larger proportion of cows in parity 3 or older in MFTs in Germany, Lithuania and Switzerland (Table 4). Variation was also observed in average age at

Table 3 Definition and name of the major farm types identified in the survey in each of the seven countries included in the analysis

\begin{tabular}{|c|c|c|}
\hline Country and code structure & Definitions of major farm types (MFT) & Name MFT \\
\hline \multirow[t]{5}{*}{ Austria AT_Barn type_Area } & $\begin{array}{l}\text { Loose housing, herd size small-medium to large; extensive/higher/alpine } \\
\text { regions }\end{array}$ & AT_Loose_Alpine \\
\hline & $\begin{array}{l}\text { Loose housing, herd size small-medium to large; intensive/favourable pro- } \\
\text { duction area }\end{array}$ & AT_Loose_Favourable \\
\hline & Loose housing, herd size small-medium to large; medium production area & AT_Loose_Medium \\
\hline & Tie-stall, herd size small to medium; higher/alpine regions & AT_Tie_Alpine \\
\hline & Tie-stall, herd size small to medium; favourable or medium production area & AT_Tie_Fav_Medium \\
\hline \multirow[t]{2}{*}{ Switzerland CH_Yield } & $\begin{array}{l}\text { Lowland (valley), high input ( } \geq 6500 \mathrm{~kg} \text { milk yield) } \\
\text { Mountain region, high input ( } \geq 6000 \mathrm{~kg} \text { milk yield) }\end{array}$ & CH_High \\
\hline & $\begin{array}{l}\text { Lowland (valley), low input }(<6500 \mathrm{~kg} \text { milk yield }) \\
\text { Mountain region, low input }(<6000 \mathrm{~kg} \text { milk yield })\end{array}$ & CH_Low \\
\hline \multirow[t]{4}{*}{ Germany DE_Scale_Yield ${ }^{1}$} & $\begin{array}{l}\text { Large-scale herds, high milk yield, typically cubicles, typically northern } \\
\text { Germany }\end{array}$ & DE_Large_High \\
\hline & Medium-scale herds, low-medium milk yield, typically eastern Germany & DE_Medium_Low/Medium \\
\hline & Medium-scale herds in southern Germany, medium milk yield & DE_Medium_Medium_South \\
\hline & $\begin{array}{l}\text { Small-scale herds, low milk yield, typically straw yards, typically western } \\
\text { Germany }\end{array}$ & DE_Small_Low \\
\hline $\begin{array}{l}\text { Denmark DK_Barn } \\
\text { type_Yield }\end{array}$ & Danish organic, loose-housed, high production & DK_Loose_High \\
\hline \multirow{4}{*}{$\begin{array}{l}\text { Lithuania LT_Barn } \\
\text { type_Herdsize }\end{array}$} & Loose housing, small ( $<80$ cows), milking parlour & LT_Loose_Small \\
\hline & Loose housing, large ( $\geq 80$ cows), milking parlour & LT_Loose_Large \\
\hline & $\begin{array}{l}\text { Tie-stall, large ( } \geq 50 \text { cows), mobile single milking machine connected to } \\
\text { milkline/bucket }\end{array}$ & LT_Tie_Large ${ }^{2}$ \\
\hline & $\begin{array}{l}\text { Tie-stall, small (<50 cows), mobile single milking machine connected to } \\
\text { milkline/bucket }\end{array}$ & LT_Tie_Small \\
\hline \multirow{3}{*}{$\begin{array}{l}\text { Poland PL_Location_Barn } \\
\text { type }\end{array}$} & Mountain regions, tie-stall and loose housing & PL_Mountain_Loosetie \\
\hline & Lowland regions, loose housing & PL_Lowland_Loose \\
\hline & Lowland regions, tie-stall & PL_Lowland_Tie \\
\hline \multirow[t]{3}{*}{ Sweden SE_MilkingEquip } & Tie-stall, mobile single milking machine connected to milkline & SE_Machine_Milkline \\
\hline & Loose housing, milking parlour & SE_Parlour \\
\hline & Loose housing, milking robot & SE_Robot \\
\hline
\end{tabular}

${ }^{1}$ All German MFT had loose housing systems. For more details of German MFT definitions, see Ivemeyer et al. (2017) MFT names: DE_Medium_Low $/$ Medium $=$ MFT A, DE_Small_Low $=$ MFT B, DE_Large_High $=$ MFT C; DE_Medium_Medium_South $=$ MFT D)

${ }^{2}$ As this MFT had only three observations, it was combined with LT_Loose_Large for statistical analysis 


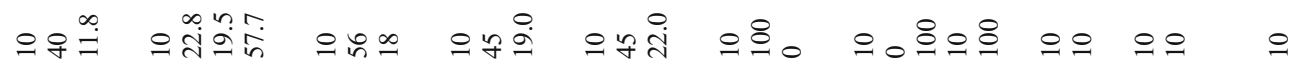

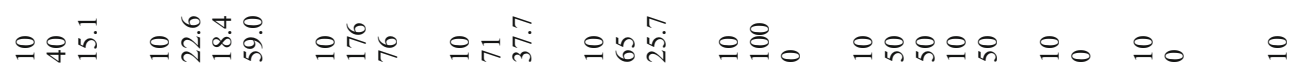

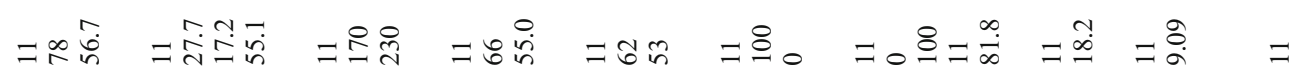

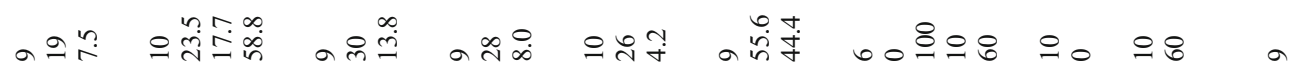
율

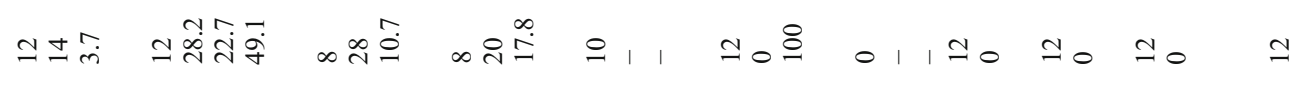

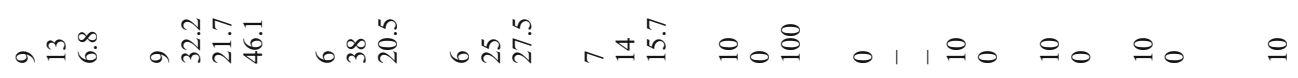

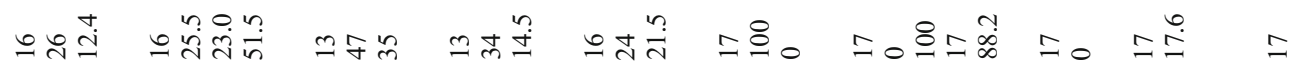
の

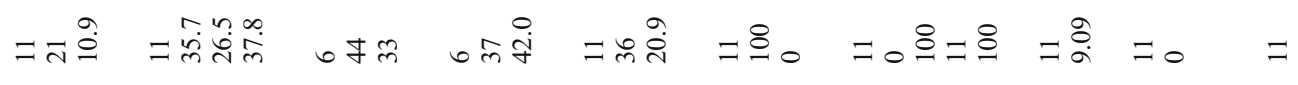

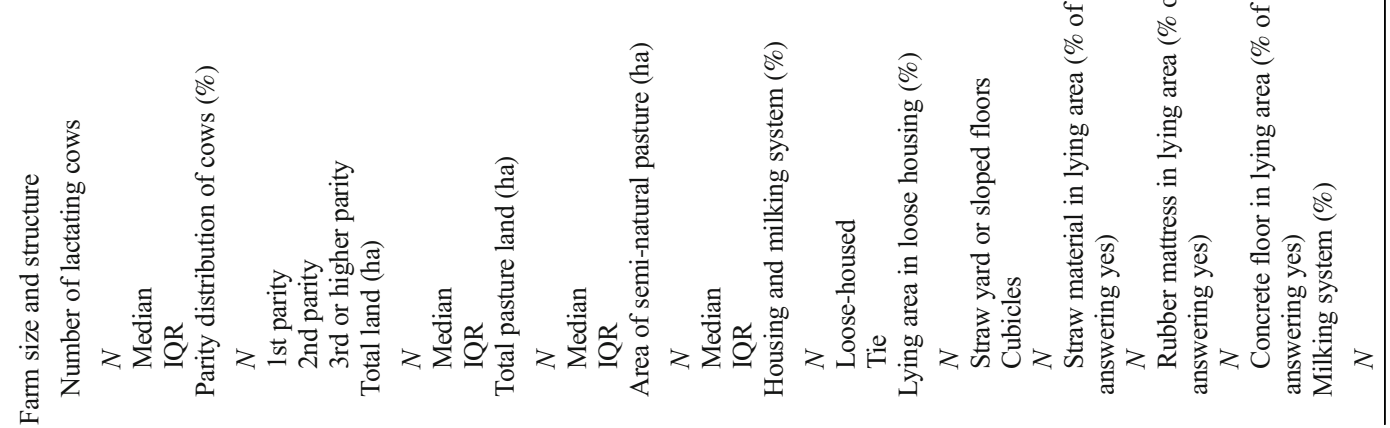




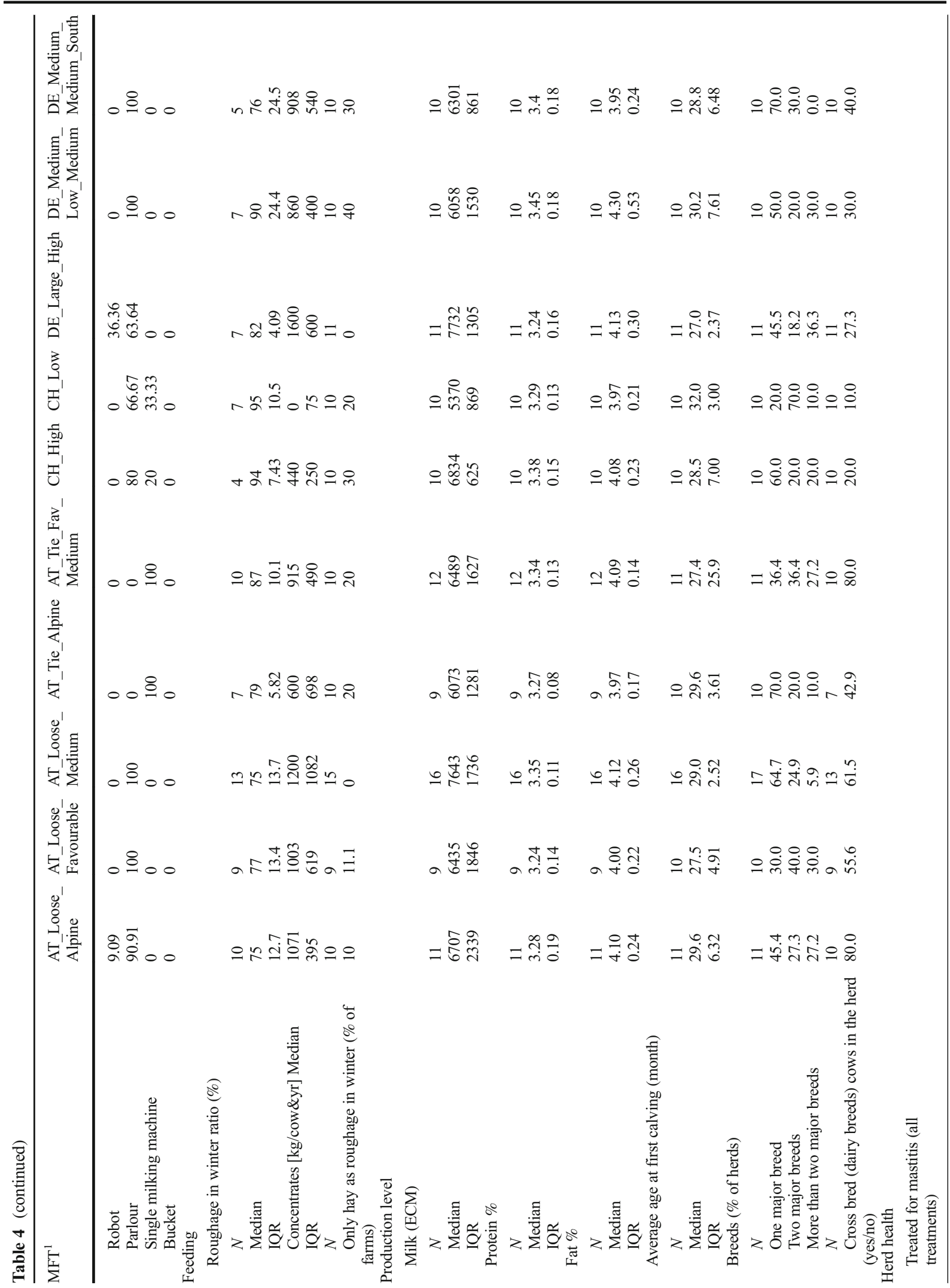




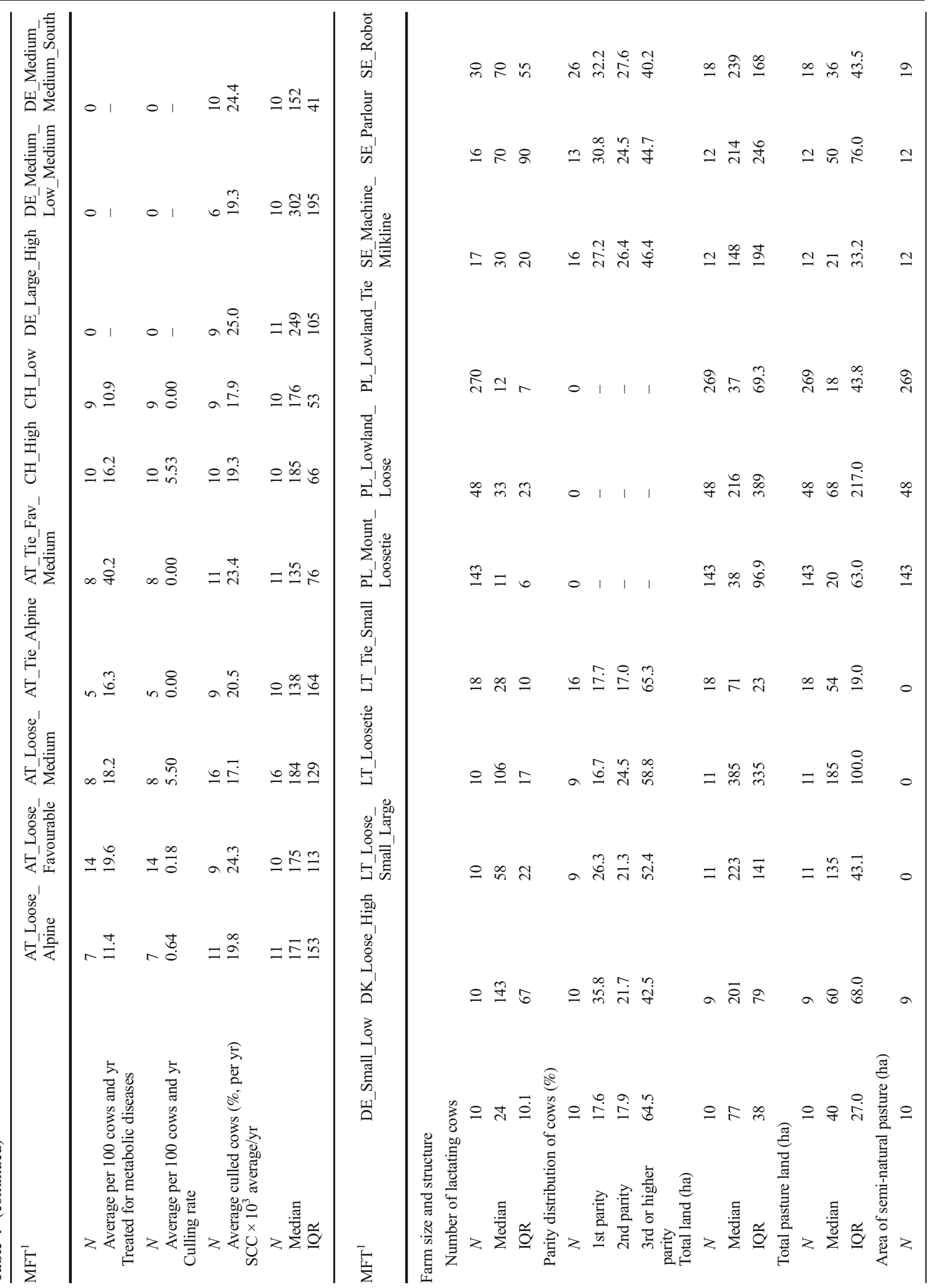




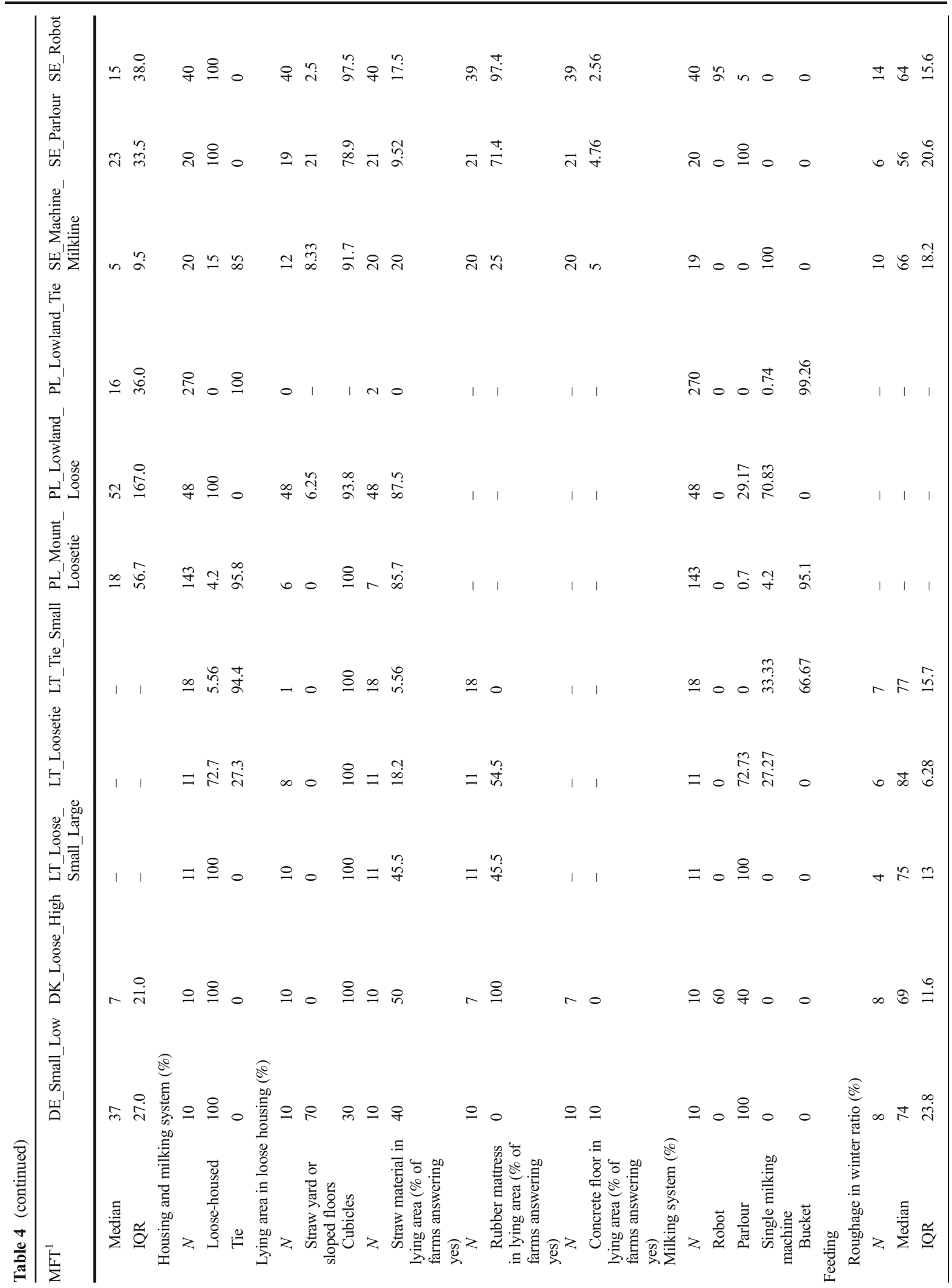




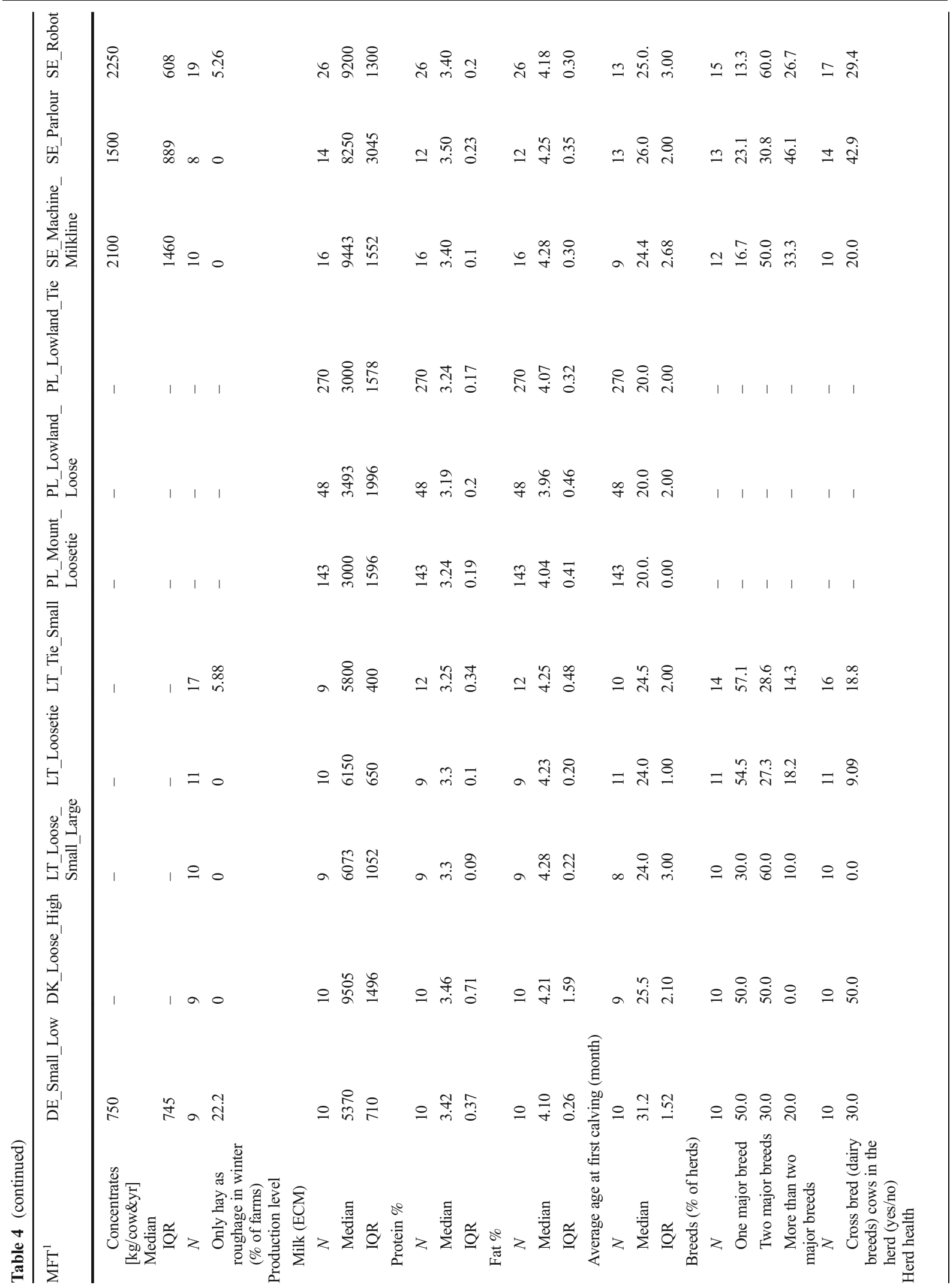




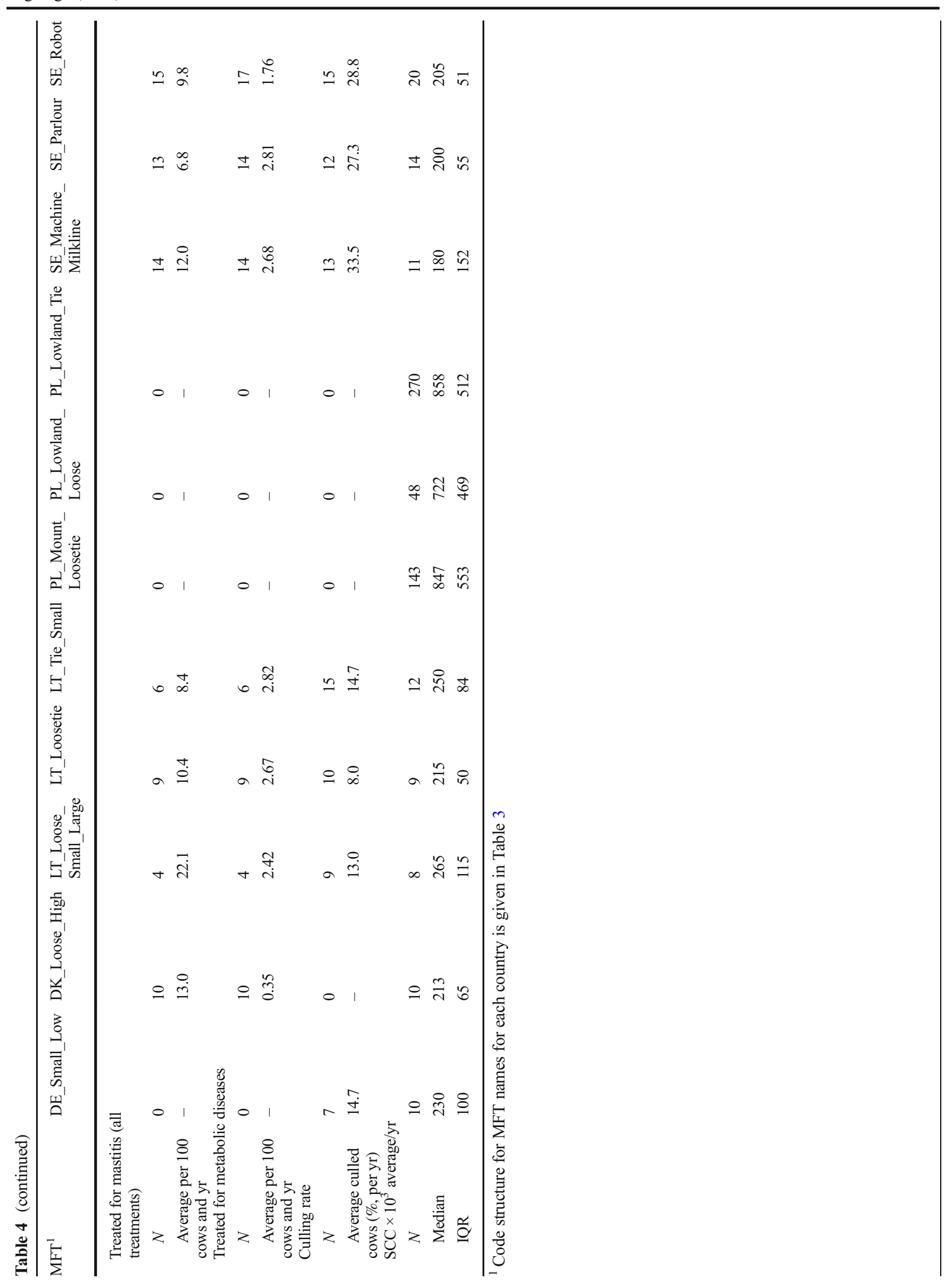


first calving, which was higher and showed greater variation in MFTs in Austria, Switzerland and Germany compared with MFTs in Denmark, Lithuania and Sweden (Table 4).

Housing and milking system

Milking and housing systems were interrelated. A milking parlour was the most common milking system in loose housing systems and a mobile single milking machine was the most common in tie-stall housing systems (Table 4). The majority of all farms had cubicles with straw in the lying area (Table 4). Farms with straw yards or sloped floors were identified as relevant housing systems within MFTs only in Germany, Sweden and Poland.

\section{Feeding strategy}

The proportion of roughage in the winter ration varied between a median of 56 and $85 \%$ on dry matter (DM) basis for the MFTs surveyed. A feeding strategy including only hay as roughage was most common among German, Swiss and Austrian MFTs (Table 4).

Production level and breeds

Median production level varied from 3000 to $9505 \mathrm{~kg}$ energy-corrected milk (ECM) per year, with the lowest production levels on Polish MFTs and the highest on MFTs in Denmark and Sweden. Milk protein and fat content varied between MFTs, but with no clear patterns. A majority of all farms had one major breed in the herd, but crossbreeds in the herd were common. The proportion of farms with only one breed was lower in MFTs in Sweden, compared with the other countries (Table 4).

Herd health and treatment routines

Average herd somatic cell count (SCC) over the year varied between a median of 135 and $858 \times 10^{3}$ cells $/ \mathrm{mL}$, with lower levels in some Austrian and Swiss MFTs and higher levels in Polish MFTs (Table 4). Most MFTs had an average mastitis prevalence of between 10 and $20 \%$ of lactating cows. Average culling rate varied between 8 and $34 \%$ of lactating cows (Table 4).

A majority of farmers on all MFTs except one (a German MFT) used antibiotics routinely for treatment of clinical mastitis. Use of the practice of drying off teat quarters and use of homoeopathic treatments varied more between MFTs, both between and within countries. A higher proportion of farmers in Lithuania and Sweden used drying off quarters as a mastitis treatment and a higher proportion of Lithuanian and Swiss farms used homoeopathic treatment (Fig. 1).

Most farms used veterinary treatments to treat metabolic disease. Homoeopathic treatment was more commonly used by farmers in Lithuania and Switzerland and small German farms (Fig. 2).

\section{Discussion}

The objectives of this study were to identify major farm types (MFT) in seven European countries, describe these MFTs and assess their critical characteristics. We identified 22 MFTs in the countries studied and entered descriptions of these MFTs into a public research database (http://projects.au.dk/coreorganicplus/researchprojects/organicdairyhealth/database-summary/), where the variation in farm characteristics is illustrated. The data collected is not, and was not intended to be, a representative sample of the organic herds in each country, as we did not intend to quantify organic dairy production characteristics. This study, and the methodology used, aimed to capture some major variations and patterns in European MFTs and the characteristics of these. The same basic protocol for data collection was used in all seven countries, but the method of data collection varied between countries, from internet-based questionnaires and compiling data from databases to telephone or in-person interviews. Differences in data collection methods, in combination with differences in management and interpretation of questions between countries and farms, may have influenced the accuracy of the answers, which must be taken into account when interpreting the results.

The results from the survey indicated that the highest milk production level and largest herd sizes are found in northern regions of Europe, i.e. Denmark, Sweden and northern Germany. The smallest herd sizes and lowest milk producution levels occur on Polish, Austrian and Swiss organic dairy MFTs, especially in mountain regions, which also displayed relatively larger variation in these characteristics. Moreover, the Lithuanian data on herd size showed great reported variation, varying from relatively small to the largest of all countries included in the survey. These results are in line with Sørensen et al. (2006), who described dairy cattle production in the 


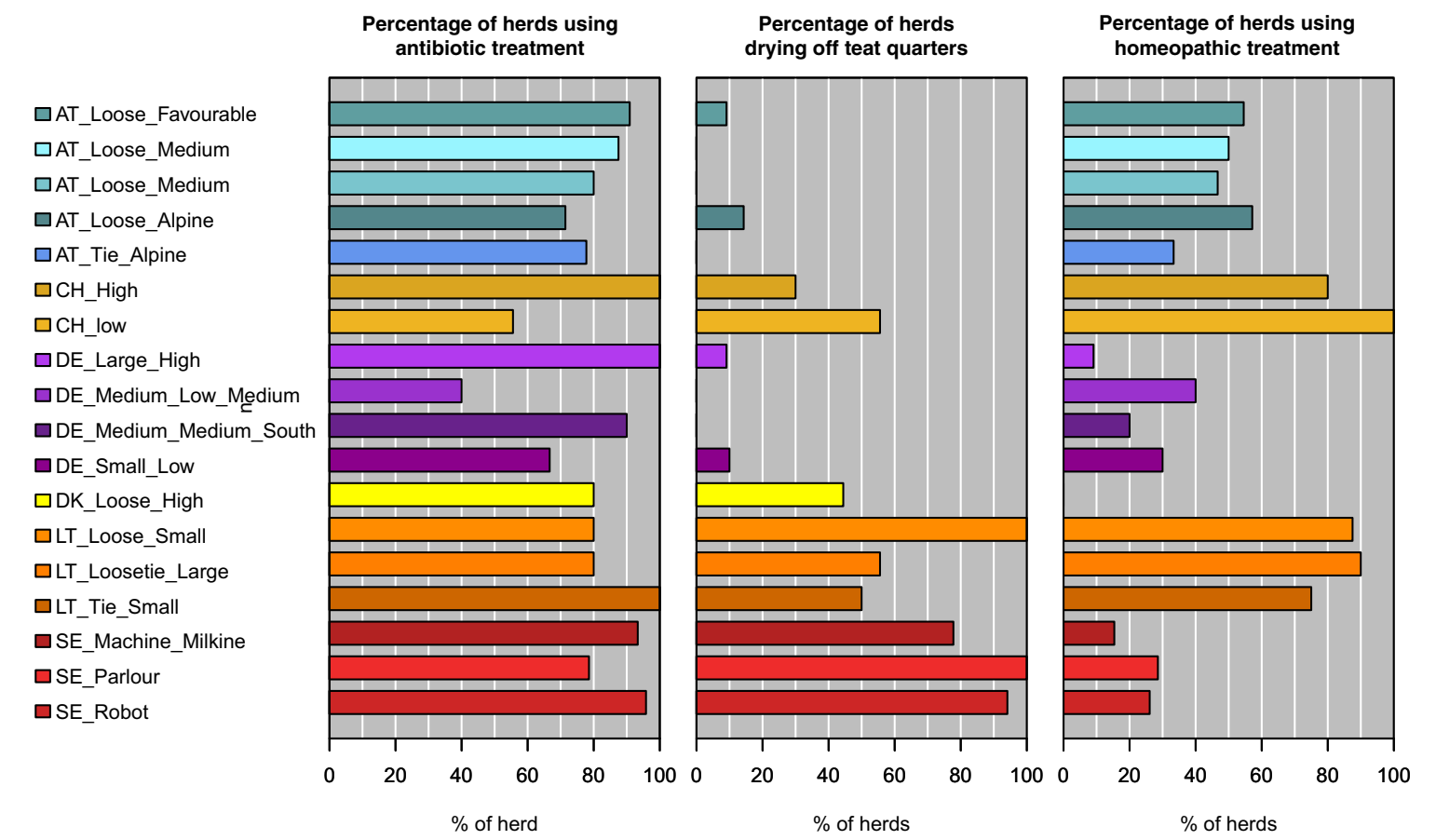

Fig. 1 Proportion of herds in different major farm types (MFTs) with routine treatment using antibiotics $(N=191)$, drying off teat quarters $(N=181)$ and homoeopathic treatment for mastitis $(N=183)$. Polish MFTs are not included, as no data were available

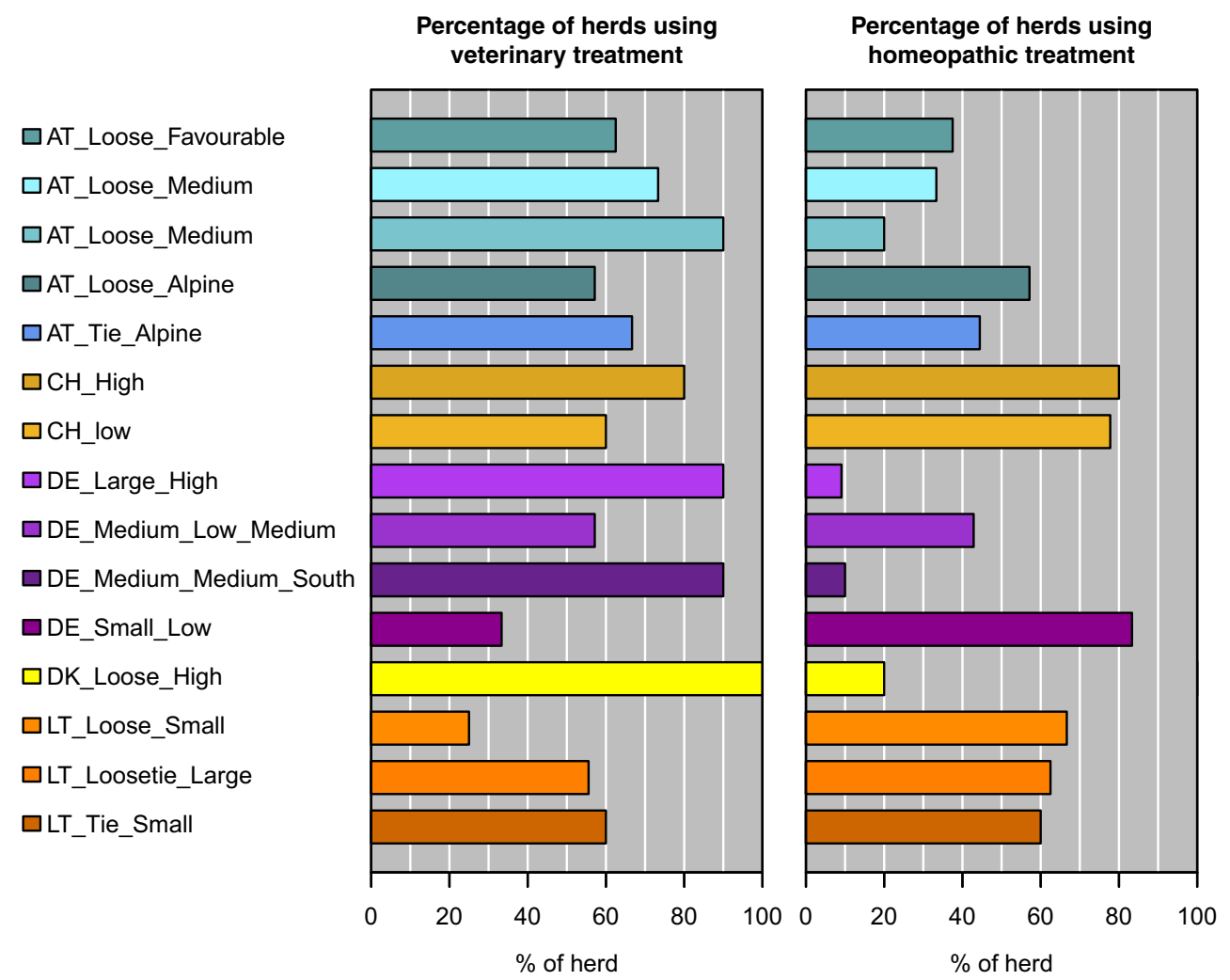

Fig. 2 Proportion of herds in different major farm types (MFTs) using routine veterinary $(N=131)$ and homoeopathic $(N=126)$ treatment for metabolic diseases. Polish and Swedish MFTs are not included, as no data were available 
industrialised world as highly specialised and with high milk production levels. However, that study also reported large differences, with dairy farms in the Netherlands, Germany, Denmark and Sweden typically being characterised as highly intensive. In the present study, we found that the countries reporting the largest variation in MFTs were Austria and Germany. These countries are situated in a region of Europe that has both lowland and mountain dairy systems. Nevertheless, in Germany, the most extreme differences between MFTs were constituted not only by topography (lowlands in the north and mountainous in the south), but more regarding production intensity (partly within the same regions; Ivemeyer et al. 2017). According to Stuaro et al. (2009), in recent decades, the number of traditional extensive farming units has decreased in favour of highly mechanised and intensive production practices and this decrease has been particularly dramatic for the traditional extensive livestock farms of the Alpine region.

Apart from herd size, the amount of farm land also varied between MFTs, indicating differences in availability of arable land for fodder production, pasture and access to semi-natural pasture. Thus, conditions for dairy production differ between regions, explaining part of the variation in dairy production systems observed in the countries and regions included in this study.

Among the farms surveyed in this study, the majority of cows were kept in loose housing systems, but there are still some tie-stall housing systems, typically in Alpine regions (Austria and Switzerland), Sweden and central Europe (Poland and Lithuania). This is in line with previous findings (e.g. Krieger et al. 2017), indicating that the farms and MFTs included in this study reflect the situation in the European dairy sector. These differences are partly explained by different conditions due to topography in mountain and lowland regions, partly by cultural, traditional and socio-economic differences and partly by differences in regulations in different countries and regions. Since 2010, EU regulations on organic production demand that cows be loose-housed, with the exception of small farms (EC 2007). However, it is not permitted to build new tie-stalls even for small farms. The threshold for 'small dairy herds' was not defined consistently in the previous version of EUs regulation (before 2018) and is instead defined at national level (Swensson 2008; Barkema et al. 2015). Countries and federal states within countries have defined these cut-offs individually, e.g. 20-35 cows, depending on federal state, in Germany, 35 livestock units in Austria, and 45 cows in Sweden
(Swensson 2008). Altogether, this indicates that a considerable proportion of the cows on organic farms in Europe are kept in tie-stalls with access to pasture during the vegetation period and regular exercise during the remainder of the year, but this proportion can be expected to decrease in the future.

Milking and housing system were found to be interrelated. A milking parlour was the most common milking system in loose-house systems and mobile single milking machine was the most common in tie-stall housing systems. Milking robot systems were used in some MFTs and seemed to be more common in regions with higher milk yields, i.e. northern Germany, Denmark and Sweden. This may partly be explained by high investment costs for automated milking systems and the need for high yields for good returns on this investment. However, it may also be attributable to differences in culture and experiences between regions, e.g. regions where automatic milking is common also in conventional dairy production (Svennersten-Sjaunja and Pettersson 2008).

According to the EU regulations on organic agriculture, at least $60 \%$ (50\% at the beginning of lactation) of the dry feed matter has to be roughage (EC 2007). The results of our survey indicate a wide range in feeding intensity on organic dairy farms. The highest values are more than $90 \%$ roughage in the dry matter ration on Swiss MFTs and typically between 80 and $90 \%$ on MFTs in Austria, Germany and Lithuania. The lowest shares of roughage in the ration (below 70\%) are used especially on all MFTs in high-yielding regions, such as in Sweden and Denmark. This variation reflects differences in national and regional regulations. For example, according to 'BioSuisse' standards of organic farming in Switzerland, the proportion of concentrates in the yearly ration for cattle-defined as cereals and grain legumes such as soybeans-may not exceed $10 \%$ of dry matter (BioSuisse, 2017). Krieger et al. (2017) observed differences in concentrate feeding levels for organic dairy farms in four European countries, with an average of 616, 1200, 1500 and $2373 \mathrm{~kg}$ concentrates per cow and year in France, Germany, Spain and Sweden, respectively. These results support our findings of a wide range between countries and of high average concentrate amounts fed in Sweden of more than $30 \%$ in the dry matter ration. Organic dairy farms in the UK are reported to use on average $1800 \mathrm{~kg}$ concentrates per year (Langford et al. 2009). Thus, our results support und complement previous findings and reflect typical variations in feeding management within the European 
organic dairy sector, caused by differences in available resources and differences in regulations between regions.

According to organic principles and standards, disease prevention must be a high priority in organic dairy production (IFOAM 2014). Disease prevention should primarily be ensured by implementing site-adapted breeding, management, nutrition and housing appropriate to the animal species (EC 2007). However, the regulations clearly state that diseased animals should be treated with appropriate methods to prevent animals suffer (e.g. antibiotic treatments in cases of serious infections). Regarding herd health, in the present study, we focused on mastitis and metabolic diseases as two important health impairments in dairy cows in general (reviewed by Martin et al. 2018 and Sundrum 2015) but also in organic dairy cows (Ivemeyer et al. 2012). Udder health was measured as arithmetic mean of somatic cell count (SCC) over 1 year from test day data and, for both udder and metabolic health, treatment incidence was used to assess disease incidence. When interpreting the results, it has to be taken into account that differences in the use of antibiotics in particular, but also other veterinary medicines, may be due not only to infection levels but also to farmers' attitudes to treatment choice (Vaarst et al. 2006; Bennedsgaard et al. 2010).

The results show a wide range of udder health conditions in the European organic sector, with the lowest SCC in Alpine and northern European regions and the highest in central European regions. While the results have to be carefully interpreted regarding absolute SCC, they are in line with other findings of similar patterns between regions. They indicate that SCC in organic herds in several European countries is on such a high level that improvements are necessary (Ivemeyer et al. 2012; Krieger et al. 2017). Mastitis treatment incidences found in the present survey support findings by Ivemeyer et al. (2012) that mastitis incidences range widely and that mastitis is a major reason for antibiotic treatment of organic dairy cows. Moreover, all treatment incidences on MFTs (average ranging from 7 to 40 treatments due to udder problems per 100 cow-years) were within the range reported in other studies (e.g. Fall and Emanuelson 2009; Bennedsgaard et al. 2010). Besides production method, management intensity has been found to have an impact on medicine use. Intensive production systems are reported to be closely associated with frequent veterinary treatment (Richert et al. 2013). However, the results from our survey did not indicate interrelations between production intensity (e.g. milk yield and feeding ratio) and treatment incidence for mastitis or metabolic diseases within organic production systems.

Interestingly, the results of the survey indicated that non-antibiotic (non-allopathic) treatment regimes varied more between regions and countries than between MFTs. While e.g. drying off single mastitic udder quarters during lactation seems to be a well-known measure in Sweden and Lithuania, and is also used by some organic farms in Switzerland and Denmark, it seems to be uncommon in Germany and Austria. The use of homoeopathic treatment also varies, being quite common in countries like Switzerland and Lithuania and less used in Denmark and Sweden. The results related to treatment strategies indicate differences between regions and countries caused by differences in regulations and culture. This emphasises the importance of cross-country and region knowledge transfer on farmer and advisor level.

The age distribution of the cows in the herds varied between MFTs, with higher proportions of first- and second-parity cows on Austrian, Danish and Swedish MFTs and higher proportions of cows in parity 3 or older on German and Lithuanian MFTs. Moreover, there was variation in average age at first calving, which was reported to be higher and to have a larger variation on MFTs in Austria, Switzerland and Germany compared with MFTs in Denmark, Lithuania and Sweden. This might partly be explained by breed differences where dual-purpose breeds, which usually have a higher age at first calving, are more common in Alpine areas. Accordingly, culling rates varied widely between MFTs. MFTs with a long productive lifetime and a low culling rate were found particularly in Lithuania. A higher culling rate than a median of $25 \%$ was found on the highyielding MFTs in Sweden and Germany. Taken together, these results could indicate differences in dairy cow recruitment strategies between regions, but are also clearly linked to production intensity, where a high intensity is connected to reduced longevity and fertility.

More than one-third of the farms surveyed had one major breed in the herd, but also kept some crossbred cows in the herd, indicating that breeding strategies including crossing of dairy breeds are widespread in the European organic dairy sector. The majority of these crosses were between high-producing dairy breeds, but crosses with native dairy breeds also occurred. The IFOAM norms for organic agriculture state that the breeds used in organic production should be adapted to local conditions, and the use of native breeds is 
promoted (IFOAM 2014). The widespread use of crossbreeds may be an indication that organic dairy farmers across Europe try to take advantage of heterosis and to benefit from both high-producing modern breeds and the functional traits of locally adapted native breeds.

One of the aims of the study was to describe characteristics of the MFTs in an open research database. The primary aim was to provide input to other work packages of the OrganicDairyHealth project, which has been achieved. A secondary aim was to make the information in the database openly available for future research projects interested in farm characteristics of organic dairy farms. Thus, information from the database summarised on MFT level has been made publicly available for anyone interested to use it for research purposes. However, as the project is finalised, there are no plans for further expansion or development of the database.

\section{Conclusions}

This survey revealed variations in herd characteristics such as production level, herd size, farm size, housing system, milking system and cow health status between organic dairy farms in seven European countries. There were also variations in management strategies such as feeding, animal health management and recruitment strategies across the organic dairy sector in Europe. These variations seem to be caused by differences between regions and countries in the conditions for organic dairy production, such as topography, land availability and regulations. Future development of organic dairy production in Europe would benefit from exchange of knowledge and experience, on farm and advisory level, across regions and countries.

Acknowledgements The authors gratefully acknowledge all farmers, experts and dairy and performance recording organisations for their cooperation and for sharing information and data. The project ORGANICDAIRYHEALTH is funded by ERA-Net CORE Organic Plus Funding Bodies partners of the European Union's FP7 research and innovation programme under grant agreement no. 618107 , and is supported by funds from The Swedish Research Council for Environment, Agricultural Sciences and Spatial Planning (FORMAS); the Federal Ministry of Food and Agriculture (BMEL) based on a decision of the Parliament of the Federal Republic of Germany via the Federal Office for Agriculture and Food (BLE) under the Federal Organic Farming Scheme (BÖLN), and grant no. 2814OE003 'Improving animal health and welfare on organic cattle milk production through breeding and management', Federal Ministry for Sustainability and Tourism (BMNT) under project numbers 100861, 101056 and 101060; The Danish Ministry of Environment and Food and the Danish Agricultural Agency; Polish National Centre for Research and Development and Polish Ministry of Agriculture and Rural Development and The Ministry of Agriculture of the Republic of Lithuania.

Open Access This article is distributed under the terms of the Creative Commons Attribution 4.0 International License (http:// creativecommons.org/licenses/by/4.0/), which permits unrestricted use, distribution, and reproduction in any medium, provided you give appropriate credit to the original author(s) and the source, provide a link to the Creative Commons license, and indicate if changes were made.

\section{References}

Barkema HW, Keyserlingk M, von Kastelic JP, Lam TJGM, Luby C, Roy J-P, LeBlanc SJ, Keefe GP, Kelton D (2015) Invited review - changes in the dairy industry affecting dairy cattle health and welfare. J Dairy Sci 98:7426-7445

Bennedsgaard TW, Klaas IC, Vaarst M (2010) Reducing use of antimicrobials - experiences from an intervention study in organic dairy herds in Denmark. Livest Sci 131:183-192

23EC (2007) Council Regulation (EC) No 834/2007 of 28 June 2007 on organic production and labelling of organic products and repealing. Regulation (EEC) No 2092/91 No. No 834/2007, Official Journal of the European Communities, L189/1 (20.07.2007)

Escribano AJ, Gaspar, P, Mesias FJ, Escribano M (2015) The contribution of organic livestock to sustainable rural development in sensitive areas. International Journal of Research Studies in Agricultural Sciences, 1(1), 21-34

European Commission (2014) Special Eurobarometer: Europeans, agriculture and the common agricultural policy. European Commission, Brussels

Eurostat (2016). Statistics on certified organic livestock by type of species. Eurostat Online database. http://ec.europa. eu/eurostat/web/agriculture/data/database. Accessed 12 Feb 2018

Fall N, Emanuelson U (2009) Milk yield, udder health and reproductive performance in Swedish organic and conventional dairy herds. J Dairy Res 76:402-410. https://doi.org/10.1017 /S0022029909990045

IFOAM (2014) The IFOAM norms for organic production and processing https://www.ifoam.bio/sites/default/files/ifoam norms_july_2014_t.pdf. Accessed June 2018

Ivemeyer S, Smolders G, Brinkmann J, Gratzer E, Hansen B, Henriksen BIF, Huber J, Leeb C, March S, Mejdell C, Nicholas P, Roderick S, Stoeger E, Vaarst M, Whistance LK, Winckler C, Walkenhorst M (2012) Impact of animal health and welfare planning on medicine use, herd health and production in European organic dairy farms. Livest Sci 145(1-3):63-72

Ivemeyer S, Brinkmann J, March S, Simantke C, Winckler C and Knierim U (2017) Major organic dairy farm types in Germany and their farm, herd, and management characteristics. Org Agric 1-17 https://doi.org/10.1007/s13165-017-0189-3

Jespersen L, Baggesen D, Fog E, Halsnæs K, Hermansen JE, Andreasen L, Strandberg B, Sørensen JT, Halberg N (2017) 
Contribution of organic farming to public goods in Denmark. Org Agric 7:243-266. https://doi.org/10.1007/s13165-0170193-7

Kristensen T, Kristensen ES (1998) Analysis and simulation modeling of the production in Danish organic and conventional dairy herds. Livest. Prod. Sci. 54, 55-65

Krieger M, Sjöström K, Blanco-Penedo I, Madouasse A, Duval JE, Bareille N, Fourichon C, Sundrum A, Emanuelson U (2017) Prevalence of production disease related indicators in organic dairy herds in four European countries. Livest Sci 198:104-108

Langford F, Rutherford K, Jack M, Sherwood L, Lawrence A, Haskell M (2009). A comparison of management practices, farmer-perceived disease incidence and winter housing on organic and nonorganic dairy farms in the UK. Journal of Dairy Research, 76(1), 6-14 https://doi.org/10.1017 /S0022029908003622

Martin P, Barkema HW, Brito LF, Narayana SG, Migior F (2018) Symposium review: novel strategies to genetically improve mastitis resistance in dairy cattle. J Dairy Sci 101:2724-2736

OrganicDairyHealth database (2018) http://projects.au. $\mathrm{d} \mathrm{k} / \mathrm{c}$ or e or g a n c p $1 \mathrm{us} / \mathrm{r}$ e s e a r c h projects/organicdairyhealth/database-summary/

Richert RM, Cicconi KM, Gamroth MJ, Schukken YH, Stigbauer KE, Ruegg PL (2013) Management factors associated with veterinary usage by organic and conventional dairy farms. $\mathrm{J}$ Am Vet Med Assoc 242(12):1732-1743. https://doi. org/10.2460/javma.242.12.1732

Röös E, Mie A, Wivstad M, Salomon E, Johansson B, Gunnarsson S, Wallenbeck A, Hoffmann R, Nilsson U, Sundberg C, Watson CA (2018) Risks and opportunities of increasing yields in organic farming. A review. Agron Sustain Dev 38(14). https://doi.org/10.1007/s13593-018-0489-3

Rosati A, Aumaitre A (2004) Organic dairy farming in Europe. Livest Prod Sci 90(1):41-51. https://doi.org/10.1016/j. livprodsci.2004.07.005
Sørensen JT, Edwards S, Noordhuizen J, Gunnarsson S (2006) Animal production systems in the industrialised world. Rev Sci Tech Off Int Epiz 25(2):493-503

Sundrum A (2015) Metabolic disorders in the transition period indicate that the dairy cows' ability to adapt is overstressed. Animals 5(4):978-1020

Svennersten-Sjaunja KM, Pettersson G (2008) Pros and cons of automatic milking in Europe. J Anim Sci 86:37-46

Swensson C (2008) Towards loose housing in Swedish organic dairy production. Poster at: Cultivating the Future Based on Science: 2nd Conference of the International Society of Organic Agriculture Research ISOFAR, Modena, Italy, 1820 June 2008. http://orgprints.org/12534/

Thomassen MA, van Calker KJ, Smits MC, Iepema GL, de Boer IJ (2008) Life cycle assessment of conventional and organic milk production in the Netherlands. Agric Syst 96(1-3):95107. https://doi.org/10.1016/j.agsy.2007.06.001

Vaarst M, Bennedsgaard TW, Klaas I, Nissen TB, Thamsborg SM, Østergaard S (2006) Development and daily management of an explicit strategy of non-use of antimicrobial drugs in twelve Danish organic dairy herds. J Dairy Sci 89(5):1842-1853

Valle PS, Lien G, Flaten O, Koesling M, Ebbesvik M (2007) Herd health and health management in organic versus conventional dairy herds in Norway. Livest. Sci. 112, 123-132

Van Wagenberg CPA, de Haas Y, Hogeveen H, van Krimpen MM, Meuwissen MPM, van Middelaar CE and Rodenburg TB (2016) Sustainability of livestock production systems: comparing conventional and organic livestock husbandry (no. 2016-035). Wageningen University \& Research

Växa (2014) Cattle statistics 2014. https://www.vxa. se/globalassets/dokument/statistik/husdjursstatistikarsredovisning-2014.pdf

Willer H and Lernoud J (2018) The world of organic agriculturestatistics and emerging trends. FiBL \& IOFAM - Organics International (2017): Frick and Bonn, 2017-02-20. 